International Journal of Current Microbiology and Applied Sciences

ISSN: 2319-7706 Volume 8 Number 03 (2019)

Journal homepage: http://www.ijcmas.com

Original Research Article

https://doi.org/10.20546/ijcmas.2019.803.163

\title{
Phylogenetic Analysis of Paramyrothecium roridum causing Brown Leaf Spot of Mulberry
}

\author{
Anil Pappachan*, K. Rahul, Debashish Chakravarty and V. Sivaprasad
}

Central Sericultural Research \& Training Institute, Berhampore, India - 742101

*Corresponding author

\section{A B S T R A C T}

\section{Keywords \\ Mulberry, Brown leaf spot, \\ Paramyrothecium roridum, Plant pathogen and phylogenetic analysis}

Article Info

Accepted:

12 February 2019

Available Online:

10 March 2019
The fungal pathogen causing brown leaf spot of mulberry was isolated in axenic form and identified as the genus Paramyrothecium based on cultural and morphological characteristics. Paramyrothecium sp. (isolate MMLS18) was identified as Paramyrothecium roridum (Tode) L. Lombard \& Crous (syn. Myrothecium roridum Tode ex. Fr.) on the basis of ITS-5.8S rDNA sequence analysis. $P$. roridum was closely related (99\%) to $P$. roridum isolates viz., NYQB452 (Raphanus sativus), HXC15051716 and HXC15051715 (Ipomoea aquatica) from China, 784 and KP10087 (Melon) from Brazil and KP10087 (Watermelon) from Pakistan. The P. roridum isolate MMLS18 (Mulberry) from India clustered within the genus Paramyrothecium and formed a clade with its closest phylogenetic relatives.

\section{Introduction}

The mulberry silkworm (Bombyx mori L.) is a monophagous lepidopteran insect feeding exclusively on mulberry (Morus spp.: Moraceae). Mulberry is a very hardy, fast growing and high biomass yielding perennial plant grown throughout the year in tropics. Foliar diseases have always been a major constraint in mulberry cultivation causing 10$30 \%$ leaf yield loss, besides reduction in leaf quality affecting the crop productivity. Brown leaf spot, bacterial leaf spot and powdery mildew are prominent mulberry diseases in the Gangetic plains of West Bengal in different seasons (Maji, 2002). Leaf spots occur largely during rainy and autumn seasons and making leaves unfit for consumption by the silkworm. Brown leaf spot caused by Myrothecium roridum Tode ex. Fr. incidence is reported from Japan (Murkai et al., 2002) and India (Maji, 2003).

More than 30 species has been reported in the Genus Myrothecium worldwide (Seifert et al., 2011), while there are 90 records in Index 
Fungorum (2019). Phylogenetic status of Myrothecium spp. is difficult to resolve based on few morphological characters and due to lack of voucher specimens with molecular data (Chen et al., 2016). The advent of DNA sequencing based technologies has redefined fungal systematics. Internal Transcribed Spacer (ITS) region of nuclear ribosomal repeat unit is the predominantly sequenced region and comparison of ITS region is widely used in determining molecular phylogeny for high degree of variation(s) between closely related species (Druzhinina and Kubicek, 2005). ITS sequences data can be considered as the primary barcode for identification of Myrothecium species, because its sequence data can reliably identify $73 \%$ of taxa studied across Fungi; has high sequence and PCR success rate (Bridge et al., 2005 and Schoch et $a l .$, 2012). In this study, phylogenetic status of Paramyrothecium roridum causing brown leaf spot in mulberry was determined using ITS5.8S rDNA sequence analysis.

\section{Materials and Methods}

\section{Location}

The present investigation was carried out at Central Sericultural Research and Training Institute (CSRTI), Berhampore, West Bengal (Latitude: $24^{\circ} 5^{\prime} 28.01 " \mathrm{~N}$ and Longitude: $\left.88^{\circ} 15^{\prime} 56.37^{\prime \prime} \mathrm{E}\right)$.

\section{Isolation of causative agent}

The brown leaf spot diseased mulberry leaves were collected from CSRTI mulberry plantation. The leaf spot lesions were cut and washed under running tap water, surface sterilized with $1 \%$ sodium hypochlorite solution for $5 \mathrm{~min}$ followed by thorough washing with sterile double distilled water. The air-dried leaf-bits were aseptically transferred onto $90 \mathrm{~mm}$ petriplates containing Potato Dextrose Agar (PDA) and plates were incubated at $25^{\circ} \mathrm{C}$ and observed for fungal growth. The fungal spores were utilized as inoculum for determining the pathogenicity of the isolate on eight month-old disease-free mulberry saplings (var. S1635) maintained under glasshouse conditions.

The leaves were sprayed with spore suspension $\left(10^{6} / \mathrm{ml}\right)$ till run-off and the plants were maintained with regular watering and observed for the development of brown leaf spot. The confirmatory pathogenicity studies were undertaken following Koch postulates.

\section{Morphological characteristics}

Colony characteristics of the fungal pathogen were recorded, while conidiophores and conidia were observed under a compound microscope. Pure cultures of MMLS18 isolate were maintained on PDA at $4^{\circ} \mathrm{C}$ and subculturing at 21 days interval.

\section{Isolation of genomic DNA and amplification of ITS}

The genomic DNA of MMLS18 isolate was extracted using Cetyl trimethyl ammonium bromide (CTAB) method. Universal primers of ITS rRNA gene (Forward-ITS1: 5'TCCGTAGGTGAACCTGCGG3'; ReverseITS4:5'TCCTCCGCTTATTGATATGC 3') were utilized for amplifying MMLS18 genomic DNA using DNA thermal cycler (Eppendorf Nexus gradient master cycler).

The PCR reaction mixture $(25 \mu l)$ consists of primers $(1 \mu \mathrm{l}$ each of forward and reverse), $2.5 \mu 1$ Template DNA, $8 \mu \mathrm{l}$ DNase-free Water and $12.5 \mu$ l Master mix (Himedia). The PCR cycle included one cycle of initial denaturation at $95^{\circ} \mathrm{C}$ for $5 \mathrm{~min}$ followed by 35 cycles of denaturation at $95^{\circ} \mathrm{C}$ for $30 \mathrm{sec}$, annealing at $55^{\circ} \mathrm{C}$ for $60 \mathrm{sec}$, extension at $72^{\circ} \mathrm{C}$ for $60 \mathrm{sec}$ and a final extension at $72^{\circ} \mathrm{C}$ for $6 \mathrm{~min}$. PCR products were stored at $4^{\circ} \mathrm{C}$ until further use. 


\section{Agarose gel electrophoresis}

The polymerase chain reaction products $(5 \mu l)$ were electrophoresed in $2 \%$ agarose gel (TAE buffer at $15 \mathrm{Vcm}^{-1}$ ) and $\mathrm{O}^{\prime} G e n e R u l e{ }^{\mathrm{TM}} 1 \mathrm{~kb}$ DNA Ladder (250-10000bp) was used as marker. The gel was stained in Ethidium bromide solution $(0.5 \mu \mathrm{g} / \mathrm{ml})$ and visualized in gel documentation system (GelDoc EZ imager of Biorad).

\section{Sequencing}

Amplified PCR products of MMLS18 isolate were sequenced employing Sanger sequencing (on ABI 3730xl 96 capillary system using Big Dye Terminator v3.1 kit) through outsourcing (M/s. Xcelris Labs, Gujarat, India).

\section{BLAST search}

To estimate the nearest phylogenetic relative of MMLS18 isolate causing brown leaf spot in mulberry, the amplicon sequence (approx. 600 bp length) was submitted to NCBI-BLAST search (http://blast.ncbi.nlm.nih.gov/Blast.cgi).

\section{Phylogenetic analysis}

The CLUSTAL W algorithm of MEGA 6.0 was used for sequence alignments and MEGA 6.0 software was used for phylogenetic analysis of individual sequences. Distances were calculated by using Kimura correction in a pair wise deletion manner. Neighbourjoining (NJ) method in the MEGA 6.0 software was used to reconstruct phylogenetic trees. Percentage support values were obtained using bootstrap procedure based on 1000 replications.

\section{Results and Discussion}

Fungal identification based on morphological characteristics (growth, color, texture and condiophore characteristics: branching, spore wall, spore size, shape and colour) is simple and direct, but is sometimes subjective. Further, related species may have similar characters making this approach less reliable and in the recent years, molecular approaches are utilized for accurate taxonomic position or phylogenetic status.

The characteristic symptoms of brown leaf spot in mulberry (S1635 variety) included brown necrotic spots, which turned to dark brown or black color surrounded by yellow hallow and varied in shapes from round to irregular. As the disease progressed, smaller spots coalesced to form blighted areas on the leaves (Fig. 1A). In advanced stages, highly infected leaves turned yellowish and defoliated prematurely. The symptoms were consistent with the observations of Belisario et al., (1999) and Kim et al., (2003). Irregularly shaped, raised, black sporodochia were observed with a white fringe of mycelia (Fig. 1B). The spore structures appeared in concentric rings within the necrotic areas and on the lower side of diseased leaves. This was obvious indication of causal agent brown leaf spot being Myrothecium (Chase, 1992 and; Byrne and Raymond, 2007). Characteristic conidiophores and conidia similar to those of genus Myrothecium were observed under microscope. The brown leaf spot infected leaf bits were placed on PDA medium for culturing of pathogenic fungi. Circular growth of fungus was observed after a period of one week which developed as white floccose colonies with sporodochia in dark green to black concentric rings bearing masses of conidia. Pathogenicity of fungi isolated was confirmed following Koch's postulates. Within two weeks of spray-inoculation on potted plants with the spore suspension, brown leaf spot symptoms were observed on the leaves and the pathogen was re-isolated from the lesions. Conidiophores were sub-hyaline to green coloured and branched bearing conidia 
terminally while Conidia were hyaline to slightly dark, one-celled, ovoid to elongate with rounded ends, (Fig. 1C and 1D) typical of $M$. roridum as evident from the descriptions of Seebold et al., (2005) and Mmbaga (2010). The isolated fungus was maintained from single spore cultures and was designated as MMLS-18 (Mulberry Myrothecium leaf Spot2018). Govindiah et al., (1989) isolated Myrothecium roridum from diseased mulberry leaves in India; whereas a new leaf spot disease caused by Myrothecium spp. was reported from Japan in 1991, which was pathogenic to 133 plant species belonging to 96 genera of 45 families. The causal fungus was identified as $M$. roridum Tode (Takahashi et al., 1994) causing brown leaf spot in mulberry. Mukarami et al., (1995) reported production of fungal toxins that cause necrosis and browning in mulberry, which belong to
Myrotoxin B and D of Trichothecenes (Murakami et al., 1999 and; Murakami and Shirata, 2005). PCR amplification of Paramyrothecium roridum (MMLS-18) ITS region resulted in $\sim 600 \mathrm{bp}$ fragment (Fig. 2). BLAST analysis revealed that MMLS-18 was 99\% homologous to $P$. roridum isolateNYQB452 (MH050392) infecting Raphanus sativus in China; $M$. roridum isolateHXC15051716 (KU312191) and HXC15051715 (KT943519) infecting Ipomoea aquatica (water spinach) in China; $M$. roridum strain-784 (JF724157) infecting melon in Brazil and $P$. roridum isolateKP10087 (KY264167) infecting watermelon in Pakistan. The BLAST analysis observations are in agreement with morphological observations and further confirming the identity of the fungal pathogen causing brown leaf spot in mulberry.

Fig.1 A. Brown leaf spot lesions on Mulberry leaf, B. Brown leaf spot lesion with black sporodochia and white fringe of mycelium, C. Conidiophore D. Conidia

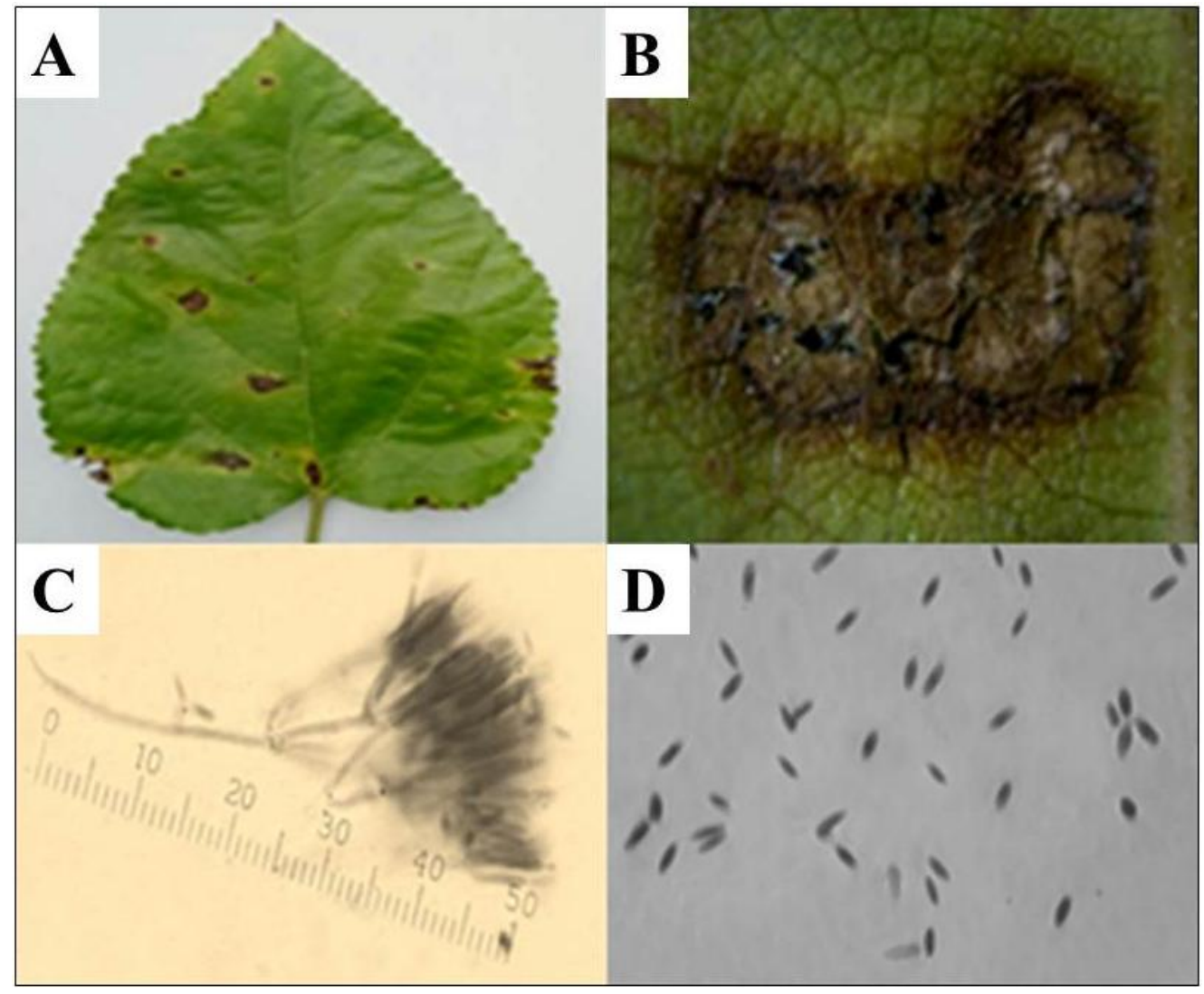


Fig.2 Amplified PCR product of ITS region of the brown leaf spot pathogen

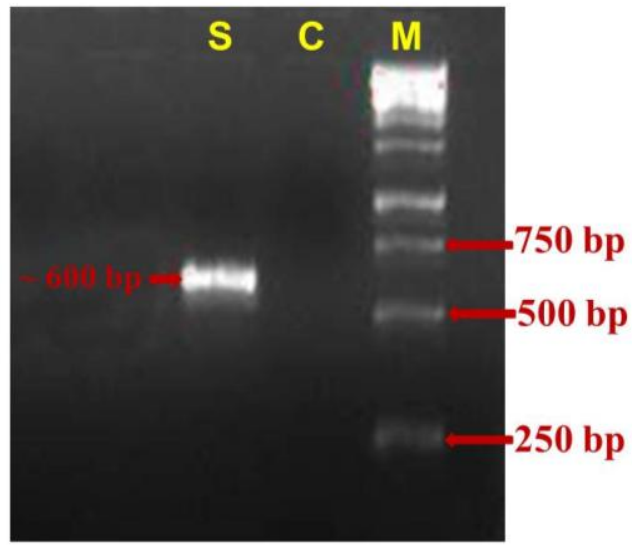

S: DNA of the causal agent amplified by ITS 1 and 4 primers, C: Control (Water), M: DNA ladder

Fig.3 NJ Phylogenetic tree based on ITS sequences showing phylogenetic relationship of the Myrothecium roridum isolate MMLS-18 with its closest phylogenetic neighbours. Numbers at nodes represent bootstrap percentages. GenBank accession numbers for ITS sequences are shown in parentheses. Bar 0.02 substitutions per nucleotide position

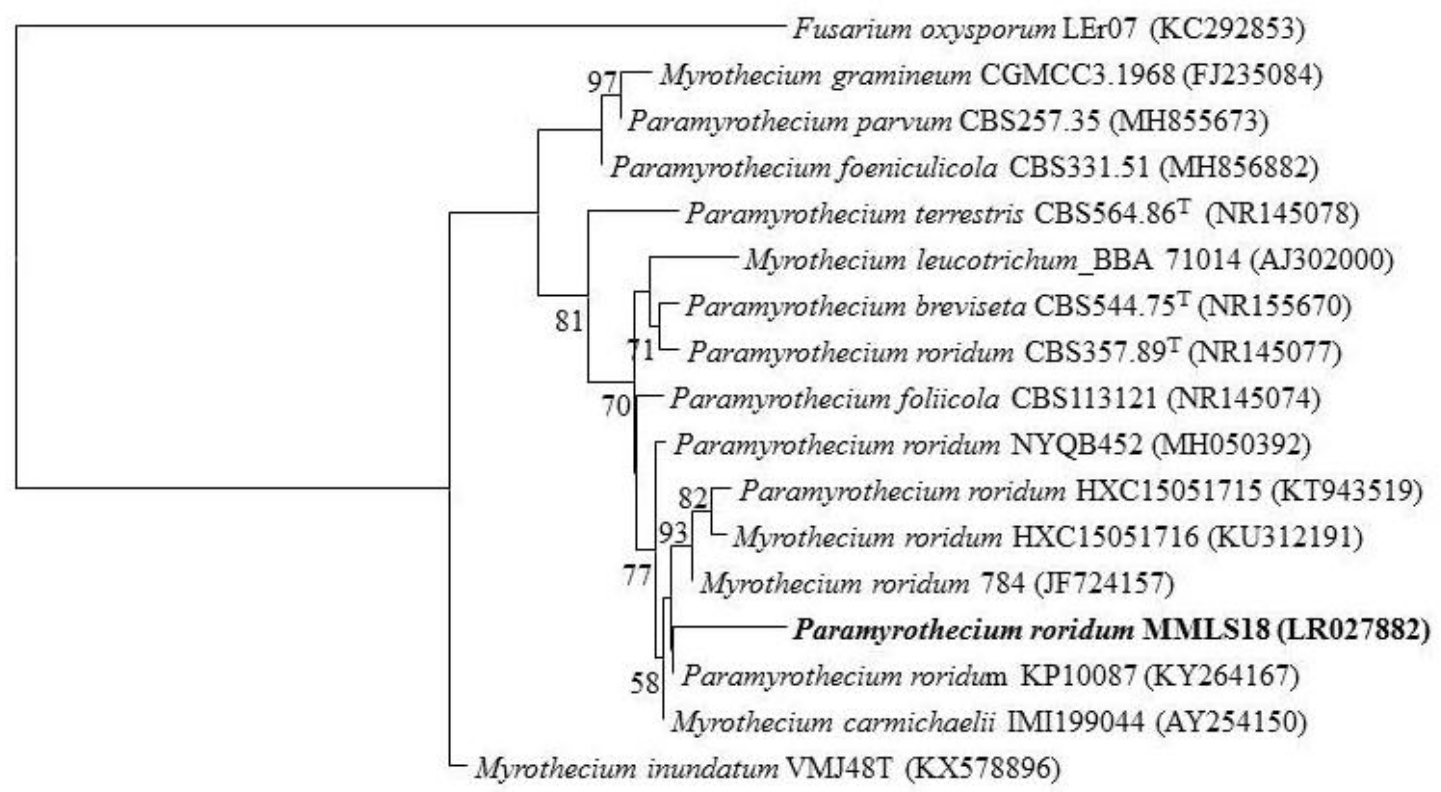

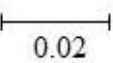

The phylogenetic analysis (Fig. 3) of the ITS sequences of the MMLS18 isolate and its closest phylogenetic neighbours indicate clustering with $M$. roridum and distancing from $M$. gramineum, $P$. parvum, $P$. foeniculicola and P. terrestris.
Analysis of ITS sequences have been employed to identify and study the diversity of genus Paramyrothecium infecting different plants which includes $M$. leucotrichum, $M$. cinctum, $M$. roridum, $M$. verrucaria, $M$. atroviride, $M$. gramineum and $M$. inundatum 
(Jonniaux et al., 2004). Similarly Okunowo et al., (2013) and Piyaboon et al., (2014) also successfully used ITS regions for identification of $M$. roridum isolated from water hyacinth. The results of present investigation are in agreement with the GenBank database sequences recorded for $P$. roridum by other researchers.

In conclusion, brown leaf spot disease of mulberry is a serious bottleneck for sericulture in Eastern and North-Eastern India. The causative fungal pathogen was identified as Paramyrothecium roridumMMLS18 (LR027882) based on ITS gene sequence analysis and morphological characteristics.

\section{References}

Belisario, A., Forti, E., Corazza, L. and Kestsren, H.A.V. 1999. First report of Myrothecium verrucaria from muskmelon seeds. Plant Pathol., 83: 589.

Bridge, P.D., Spooner, B.M. and Roberts, P.J. 2005. The impact of molecular data in fungal systematics. Adv. Bot. Res., 42: 33-67.

Byrne, J. and Raymond A.C. 2007. A pocket guide for IPM Scouting in herbaceous perennials. MSU Extension (publication E-2981).

Chase, A.R. 1992. Myrothecium Leaf Spot. Compendium of Ornamental Foliage, APS press, Minnesota. Plant Disease, pp. 35-37.

Chen, Y., Ran, S.F., Dai, D.Q., Wang, Y., Hyde, K.D., Wu, Y.M. and Jiang, Y.L. 2016. Mycosphere Essays 2. Myrothecium, Mycosphere, 7 (1): 64-8.

Druzhinina, I. and Kubicek C. P. 2005. Species concepts and biodiversity in Trichoderma and Hypocrea: from aggregate species lo species cluster? $J$. Zhejiang Univ. Sci. B. 6(2):100-12.
Govindiah, Sengupta, K., Sharma, D.D., Gargi and Gunasekhar. 1989. A new leaf spot disease of mulberry caused by Myrothecium roridum Tode ex Fr. Curr Sci., 58: 398.

Index Fungorum, 2019, http://www. indexfungorum.org/names/Names.asp

Jonniaux, J.L., Valepyn, E., Corbisier, A.M. and Dauvrin, T. 2004. Myrothecium sp. transformation and expression system. World Intellectual Property Organisation, Patent WO.

Kim, D.K., Bae, D.W., Lee, S.C., Han, K.S. and Kim, H.K. 2003. Detection of Myrothecium leaf spot, a new disease of watermelon. Plant Pathology J., 19: 200-202.

Maji, M.D. 2002. Mulberry diseases of the Gangetic plain of West Bengal and their control. Indian silk, 41: 11-15.

Maji, M.D. 2003. North Eastern states: Mulberry diseases and their management. Indian silk, 42: 7-10.

Mmbaga, M.T. 2010. First report of Myrothecium roridum causing leaf spot on Garden Hydrangea in the United States. School of Agriculture and Consumer Science, Otis Floyd Nursery Crops Research Center, Tennessee State University, McMinnville, 94(10): 1266.1

Murakami, R., and Shirata, A. 2005. Myrotoxin B detection from mulberry leaves infected with Myrothecium roridum, cause Myrothecium leaf spot of mulberry, and possible roles in pathogenicity, J. J. Phytopath., 71(2): 91-100.

Murakami, R., Shirata, A., Yoshida, S., Segawa, H. and Takahashi, K. 1995. Differences in size of lesions on leaves infected with Myrothecium roridum Tode ex Fries in mulberry cultivars. Bull. Natl. Inst. Seric.Entomol. Sci., 12: 31-46.

Murakami, R., Yasui, H., Shirata, A. and 
Kato, A. 1999. Production of Myrotoxin B by Myrothecium roridum isolated from Myrothecium leaf spot of mulberry in Japan. J. Seric. Sci. Jpn., 68:469-77.

Murkai, R., Kawakita, H. and Shirata, A. 2002. Infection behavior of conidia of Myrothecium roridum on mulberry leaf and cytological changes of leaf cells infected with the fungus. Sericologia, 42: 19-31.

Okunowo, W.O., Osuntokia, A.A., Adekunlec, A.A. and Gbenlea, G.O. 2013. Occurrence and effectiveness of an indigenous strain of Myrothecium roridum Tode: Fries as a bioherbicide for water hyacinth (Eichhornia crassipes) in Nigeria. Biocontrol Sci. Technol. 23(12):1387-1401.

Piyaboon, O., Unartngam, A. and Unartngam, J. 2014. Effectiveness of Myrothecium roridum for controlling water hyacinth and species identification based on molecular data, Afr. J. Microbiol. Res., 8(13): 1444-1452.

Qadri, S.M.H., Gangwar, S.K., Pratheesh Kumar, P.M., Elangavon, C., Maji, M.D. and Saratchandra, B. 1999. Crop loss assessment due to leaf spot disease of mulberry. Indian J. Sericulture, 38(1): 35-39.

Schoch, C.L., Seifert, K.A., Huhndorf, S., Robert, V., Spouge, J.L., Levesque, C.A. and Chen, W. 2012. Fungal Barcoding Consortium-Nuclear ribosomal internal transcribed spacer (ITS) region as a universal DNA barcode marker for Fungi. Proceedings of the National Academy of Science, 109: 6241-6246.

Seebold, K.W., Langston, D.B. and Kemerait, R.C. 2005. First report on leaf and stem canker caused by $M$. roridum on water melon. Plant Dis., 89(3): 342.

Seifert, K.A., Morgan-Jones, G., Gams, W. and Kendrick, B. 2011. The genera of Hyphomycetes. CBS, The Netherlands, 1-997.

Takahashi, K., Segawa, H. and Kobayashi, T. 1994. Myrothecium leaf spot of mulberry caused by Myrothecium roridumTode: Frides. Ann. Phytopath. Soc. Jpn., 60: 122-127.

Wipf, D., Fribourg, A., Munch, J.C., Botton, B. and Buscot, F. 1999. Diversity of the Internal Transcribed Spacer of rDNA in Morels. Can. J. Microbiol., 45: 769778.

\section{How to cite this article:}

Anil Pappachan, K. Rahul, Debashish Chakravarty and Sivaprasad, V. 2019. Phylogenetic Analysis of Paramyrothecium roridum causing Brown Leaf Spot of Mulberry. Int.J.Curr.Microbiol.App.Sci. 8(03): 1393-1399. doi: https://doi.org/10.20546/ijcmas.2019.803.163 